\title{
Pattern of Liver Function Tests in Spectrum of Acute Viral Hepatitis
}

Shagufta Yousaf ${ }^{1}$, Mohammad Younas ${ }^{2}$, Ghulam Murtaza ${ }^{3}$, Fahim Akhtar ${ }^{4}$, Syed Raza Jaffar ${ }^{5}$, Aamir ljaz ${ }^{6}$

\section{ABSTRACT}

Objective: To find out the pattern of Liver Function tests (LFTs) in different spectrums of Acute Viral Hepatitis (AVH).

\section{Study Design: Cross sectional.}

Place and Duration of Study: The study was conducted at Pathology Department of Combined Military Hospital, Malir Karachi from March 2017 to August 2017.

Materials and Methods: A total of 360 subjects of all age groups, both male and female, with biochemical features of acute viral hepatitis (AVH) were included. After clinical history and examination, liver function tests (LFTs) were performed that included total bilirubin, alanine amino transferases (ALT), alkaline phosphatase (ALP), followed by viral markers for hepatitis A virus (HAV), hepatitis B virus (HBV) hepatitis C virus (HCV) and hepatitis Evirus (HEV).

Results: Among the 360 patients studied, males ( $n=308,86 \%$ ) outnumbered females ( $n=52,14 \%)$. Biochemical pattern showed ALT value reaching $>75$ times the upper limit of normal (ULN). Similarly rise of serum total bilirubin was up to 30 times of ULN while rise of serum ALP was not more than 5 times of ULN. HEV was found to be the most common (28\%) in seropositive AVH in the study group. Highest number (24.4\%) of HEV infection was found among males in the age group of 20-30 years. ALT and bilirubin were significantly raised in patients with HEV as compared to other causes of AVH.

Conclusion: Pattern of LFTs varies in spectrum of AVH. Highest rise of ALT indicates extensive liver damage in HEV infection.

Key Words: AVH, HEV, LFTs.

How to cite this: Yousaf S, Younas M, Murtaza M, Akhtar F, Jaffar SR, ljaz A. Pattern of Liver Function Test in Spectrum of Acute Viral Hepatitis. Life and Science. 2020; 1(1): 28-32. doi: http://doi.org/10.37185/LnS.1.1.38

\section{Introduction}

Viral hepatitis is an epidemic worldwide and over 13 million people suffer in Pakistan while in Asia pacific region one person dies every 30 second from hepatitis. ${ }^{1}$ Deaths of 1.44 million, were identified by Global Burden of Disease Study 2010 (GBD 2010) due

\footnotetext{
1,2 Department of Chemical Pathology/ Hematology Karachi Institute of Medical Sciences Combined Military Hospital, Malir

${ }^{4}$ Department of Chemical Pathology Combined Military Hospital, Mangla ${ }^{5}$ Department of Chemical Pathology Army Medical College, Rawalpindi ${ }^{6}$ Department of Chemical Pathology Rehman Medical College, Peshawar Correspondence:

Dr. Shagufta Yousaf

Department of Chemical Pathology Karachi Institute of Medical Sciences Combined Military Hospital, Malir E-mail:malausaf@gmail.com

Funding Source: NIL; Conflict of Interest: NIL Received: Feb 02, 2019; Revised: Nov 18, 2019 Accepted: Dec 04, 2019

28
}

to viral hepatitis, this accounted for $2.7 \%$ of all deaths in that year. ${ }^{2}$ World Health Organization (WHO) and other collaborators conduct "World Hepatitis Day" on 28th of July every year to enhance the public awareness and intensify the preventive and control measures for viral hepatitis. ${ }^{2}$

In Pakistan, major cause of acute viral hepatitis (AVH) is hepatitis E virus (HEV) especially in adults belonging to lower socioeconomic groups. ${ }^{3}$ Hepatitis A virus (HAV) and HEV accounted for 159,400 deaths globally in 2010., Pakistan Field Epidemiology and Laboratory Training Program (FELTP) supported by the Center for Disease Control and Prevention (CDC) USA reported 712 new cases of viral hepatitis during June 2010 and March 2011 with Hepatitis C virus (HCV) infection accounting for $53.2 \%$ of newly reported cases, followed by HAV (19.8\%) and HEV $(12.2 \%) .^{5}$ Till now six distinct types of hepatitis viruses have been isolated and named as hepatitis $A$, $B, C, D, E$ and $G$ viruses. ${ }^{6}$ More than 10 million people in Pakistan are living with HCV infection. The 
mortality rate for HEV is low (1-2\%), except in pregnant females (15-20\%). ${ }^{8}$ Chronic HEV is now sporadically seen in organ transplant recipients, patients on hemodialysis, HIV patients and those with hematological malignancies. ${ }^{9}$ If left untreated, it may eventually progress to cirrhosis among immunocompromised patients. ${ }^{10,11}$ An outbreak of HEV infection had also occurred in cruise ship because of use of seafood. ${ }^{12}$ In severe instances, it can result in acute fulminant liver failure, disability and death. ${ }^{13}$

Hepatitis $A$ and $E$ are enterically transmitted, selflimiting AVHs. The risk factors identified for HAV and HEV infections include unsafe or contaminated food and water and poor sanitary conditions ${ }^{5}$, while HBV and HCV infections are transmitted through blood and other body fluids. ${ }^{6}$ The onset of acute hepatitis is typically 2 to 24 weeks after exposure and it is unlikely to occur after 52 weeks or earlier than 4 days. ${ }^{13}$ Patient presents with insidious onset of symptoms including fever, malaise, nausea, vomiting, deep yellow color of urine and pain abdomen, while signs include jaundice, pallor and tender hepatomegaly. At present HEV of two distinct origins has been identified in Pakistan based on genotype, namely Sar-55 from Central Asian origin and Abb-2B from South Asia. Of these, Abb-2B is believed to be endemic in Pakistan. ${ }^{14}$ Early diagnosis of HEV infection is very important and timely management can prevent life threatening condition like acute fulminate hepatic failure but investigation for confirmation of HEV is routinely not performed, however monitoring of biochemical parameters of liver function tests (LFTs) remains very helpful in this situation. There are few published studies on biochemical pattern of LFTs to help in differentiating the causes of AVH especially in our population. This study was planned to highlight the importance of LFTs in different spectra of AVH.

\section{Materials and Methods}

The study was conducted at Department of Pathology, Combined Military Hospital, Malir Karachi from March to August 2017, after the approval of the institutional review committee. Patients with clinical or biochemical features of acute hepatitis were included in the study. Patients with clinical or ultrasonographic evidence of biliary obstruction, chronic hepatitis B and C or chronic liver disease were excluded. A total of 360 patients were selected over a period of six months with nonprobability random sampling technique. Clinical profiles of the patients were recorded and LFTs were performed on Selectra Pro $\mathrm{M}$ chemistry analyzer, that includes serum bilirubin done by modified Jendrassik and Groff method. Serum ALT and ALP were done by Kinetic methods. Upper limit of normal (ULN) was 17umol/L for bilirubin, $40 \mathrm{IU} / \mathrm{L}$ for ALT and $170 \mathrm{IU} / \mathrm{L}$ for ALP. All patients were tested for hepatitis $B$ surface antigen ( $\mathrm{HBsAg}$ ) by Enzyme Labeled Immuno Sorbent Immunoassay (ELISA). Antibody to hepatitis $C$ Virus (anti-HCV) was measured by $3^{\text {rd }}$ generation ELISA. Sample for IgM HAV and HEV were sent to Armed Forces Institute of Pathology Rawalpindi (AFIP) for analysis. All patients were followed up for complete clinical and biochemical recovery. Statistical analysis was done on SPSS 20.

\section{Results}

Among the 360 patients studied, males (86\%) outnumbered females (14\%) (Table 1). Maximum numbers of cases were young adults. Most common age group was 20 to 30 years (Figure-1). Seronegative hepatitis significantly outnumbered $(n=220,61 \%)$ the seropositive hepatitis ( $n=140,39 \%)$ cases. Highest number (24.4\%) of HEV infection was found among the age group of $20-30$ years (Figure1). HEV infection was found to be the most common $(28 \%)$ in seropositive AVH in the study group (Figure2). Surprisingly all were males. HCV infection was found in 24 (7\%) patients, whereas HBV infection in $12(3 \%)$. HAV was positive only in $4(1 \%)$ patients in age group $<20$ years (Figure-1). We found a relative sparing of age groups below 10 years.

Biochemical spectrum of LFTs in seronegative AVH showed that maximum rise of serum bilirubin was up to $540 \mathrm{umol} / \mathrm{I}$ about 30 times of ULN. Maximum rise of ALT was $>75$ times of ULN (3210 U/L) with an average rise up to $1763 \mathrm{U} / \mathrm{L}$ seen in 68 cases and maximum rise of serum ALP was 2890 in a single case whereas it was 2-5 times of ULN seen in 184 cases (Table 2). In seropositive $\mathrm{AVH}$, maximum rise of bilirubin was $130 \mathrm{umol} / \mathrm{l}$ in $\mathrm{HEV}, 57 \mathrm{umol} / \mathrm{l}$ in HBV, $109 \mathrm{umol} / \mathrm{l}$ in HAV and $31 \mathrm{umol} / \mathrm{l}$ in HCV (Figure 3), while maximum rise of serum ALP was 680 and 508 $\mathrm{U} / \mathrm{L}$ in $\mathrm{AVH} A$ and $E$ respectively. ALT was raised in almost $90 \%$ of AVH patients, being remarkably raised $(1020 \mathrm{U} / \mathrm{L})$ in $\mathrm{HEV}$, whereas maximum rise noted in 
$\mathrm{HAV}$ was $723 \mathrm{U} / \mathrm{L}, 363 \mathrm{U} / \mathrm{L}$ in HBV and $63 \mathrm{U} / \mathrm{L}$ in HCV, which was statistically significant, $p$ value $<0.05$ (Table 3). Four patients progressed to acute fulminate hepatic failure. Two cases were diagnosed with hepatitis $E$ and the other two cases had seronegative hepatitis. Except for these four patients, all gradually recovered. In general, there was greater rise of all parameters of LFTs in HEV indicating extensive liver damage than other types of seropositive AVH.

\begin{tabular}{lcc}
\hline \multicolumn{3}{l}{ Table 1: } \\
\hline Gender & No of Cases & Percentage \\
Male & 308 & $86 \%$ \\
Female & 52 & $14 \%$ \\
Total & 360 & $100 \%$ \\
\hline
\end{tabular}

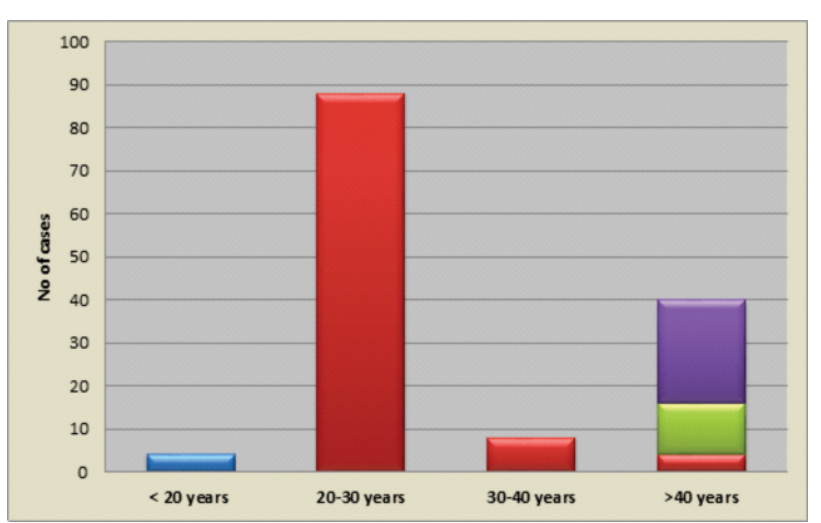

Fig 1: Age Wise Distribution of the AVH Cases $(\mathrm{N}=360)$ ( $\square=\mathrm{HEV}, \square=\mathrm{HAV}, \square=\mathrm{HCV}, \square=\mathrm{HBV}$ )

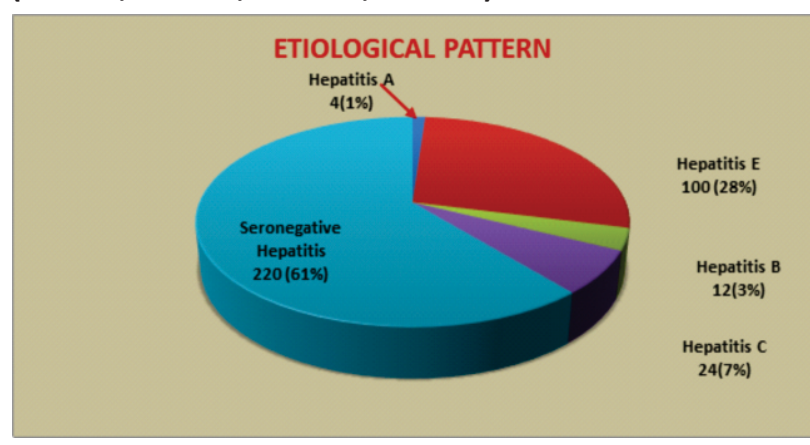

Fig 2: Etiological Pattern of AVH Cases $(\mathrm{N}=360)$

\begin{tabular}{|c|c|c|c|c|}
\hline LFTs & $\begin{array}{l}\text { Maximum } \\
\text { Rise }\end{array}$ & Values & $\begin{array}{l}\text { No of } \\
\text { Cases }\end{array}$ & Mean \\
\hline $\begin{array}{l}\text { S. Total } \\
\text { Bilirubin }\end{array}$ & 540 & $\begin{array}{r}10- \\
200 \\
> \\
200\end{array}$ & 312 & 346 \\
\hline S. ALT & 3210 & $\begin{array}{r}40- \\
1000 \\
>1000\end{array}$ & 68 & 1763 \\
\hline S. ALP & 2890 & 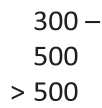 & $\begin{array}{l}184 \\
176\end{array}$ & $\begin{array}{l}326 \\
818\end{array}$ \\
\hline
\end{tabular}

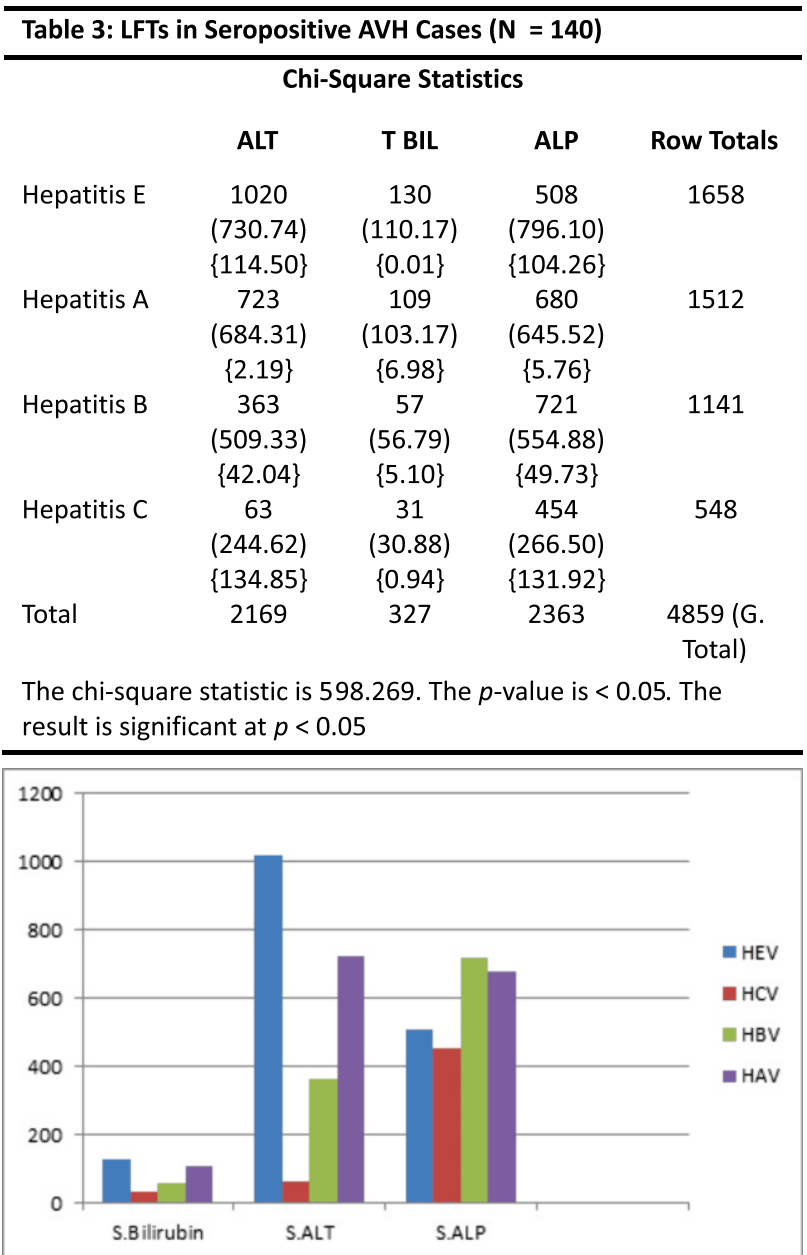

Fig 3: LFTs in Seropositive AVH Cases ( $N=140)$

\section{Discussion}

Viral hepatitis is a major cause of morbidity and mortality worldwide and an increasing cause of concern in Asian population. Whether it is water, food or blood born hepatotropic virus, increasing burden is alarming. According to the guidelines and recommendation given by National Academy of Clinical Biochemistry on use of laboratory tests in the diagnosis and monitoring of hepatic injury, AVH can be diagnosed by ALT $>10$ times of ULN and ALP $>2$ times of ULN. ${ }^{15}$ In our study, we have found that ALT can rise $>75$ times of ULN whereas ALP $>2$ but $<5$ times of ULN. The commonest cause of AVH was seronegative hepatitis (61\%) than seropositive hepatitis. HEV was the major cause of seropositive AVH $(28 \%)$, same was also observed by Butt $\mathrm{AS}^{16}$ where in HEV infection occurred in $20-22 \%$ of $A V H$ cases. In our study, prevalence of HEV infection in the age group of $20-30$ years was $24.4 \%$ and same was also found by Malik IA. ${ }^{17}$ Predominantly, males were 
affected and this was also observed by Bengu said et al. ${ }^{11}$; but contrary to the findings of Teshale $\mathrm{EH}^{18}$ which reported higher number of females. Biochemically, HEV infection presentation was different than other causes of AVH as bilirubin and ALT were markedly raised in HEV as compared to HAV. Das et al. ${ }^{19}$ reported no clinical or biochemical difference in spectrum of $\mathrm{AVH}$, which were contrary to our findings but similar to the results reported by Azim et al..$^{20}$ It showed better correlation between biochemical parameters such as ALT, bilirubin and ALP in HEV, as evident by statistical significance ( $p$ value $<0.05$ ). Significant correlation of serum bilirubin, ALT and ALP in HEV is also reported in our study, indicating both impaired conjugation and cholestasis by affected hepatocytes while less conjugation defect in other spectra of AVH. Maximum and rapid hepatocellular damage was more in HEV, it can be simply diagnosed by biochemical monitoring of patient. This study showed the significance of biochemical parameters for diagnosis and management of $\mathrm{AVH}$ and HEV infection. Knowledge and interpretation of these tests are vitally important. At present, no vaccine is available for HEV infection, but available against HAV and $\mathrm{HBV}^{21}$ As per the findings of our study it reinforces that HEV continues to be the commonest cause of seropositive AVH thereby emphasizing the need for rapidly available investigation like LFTs that help in diagnosis of HEV. This study was a single center study carried out at $\mathrm{CMH}$ Malir, not representing the entire population of Pakistan; however, it does provide valuable information on the importance of LFTs in different spectra of AVH. More multicenter studies with similar selection criteria throughout the country would better enable us to evaluate the complete biochemical pattern in AVH.

\section{Conclusion}

HEV infection remains a significant cause of seropositive $\mathrm{AVH}$. The biochemical pattern of LFTs is different in HEV than other spectra of AVH. Highest rise of ALT indicates extensive liver damage in HEV that remains a significant cause of sporadic AVH in our study population.

\section{REFERENCES}

1. Khan A, Tanaka Y, Kurbanov F, Elkady A, Abbas Z, Azam Z, et al. Investigating an outbreak of acute viral hepatitis caused by hepatitis E virus variants in Karachi South Pakistan: J Med. 2011; 83:622-9.

2. Abbas Z, Afzal R. Addressing viral hepatitis in Pakistan: not all is gloom and doom. J Coll Physicians Surg Pak. 2014; 24: 75-7.

3. Alavian SM, Fallahian F, Lankarani KB. Epidemiology of hepatitis $\mathrm{E}$ in Iran and Pakistan. Hepatitis monthly. 2009; 9: 60-5.

4. Arankalle VA, Chadha MS, Tsarev SA, Emerson SU, Risbud $A R$, Banerjee $K$, et al. Seroepidemiology of water-borne hepatitis in India and evidence for a third entericallytransmitted hepatitis agent. Proc Natl Acad Sci. 1994; 91: 3428-32.

5. Safdar RM, Salman M, Asghar RJ, Soomro AK, Mohsin A, Kazi $\mathrm{BM}$, et al. Centers for Disease Control and Prevention (CDC). Establishment of a viral hepatitis surveillance system Pakistan, 2009-2012. Morb Mortal Wkly Rep. 2011; 60: 1385-90.

6. Bosan A, Qurashi H, Bile KM, Ahmad I, Hafiz R. A Review of Viral Hepatitis in Pakistan. J Pak Med Assoc: 2010; 60: 10458.

7. Waheed Y, Shafi T, Safi SZ, Qadri I. Hepatitis C virus in Pakistan: a systematic review of prevalence, genotypes and risk factors. World J Gastroenterol: 2009; 15: 5647-53.

8. Harris KR, Dighe AS. Laboratory testing for viral hepatitis. Am J Clin Pathol. 2002; 118: 18-25.

9. Legrand-Abravanel F, Kamar N, Sandres-Saune K, Garrouste C, Dubois M, Mansuy JM, et al. Hepatitis E virus infection in solid-organ transplant recipients in France. J Infect Dis: 2010; 202: 835-44.

10. Abbas Z, Afzal R. Hepatitis E: when to treat and how to treat. Antivir Ther. 2014; 19: 125-31.

11. Sultana R, Humayun S. Fetomaternal outcome in acute hepatitis E. J Coll Physicians Surg Pak. 2014; 24: 127-130.

12. Said B, ljaz S, Kafatos G, Booth LH, Thomas HL, Walsh A, et al. Hepatitis E Outbreak on Cruise Ship. EID. 2009; 15: 1738-44.

13. Shahzad F, Atiq M, Ejaz S, Hameed S. Hepatitis E: Review of a disease endemic in Pakistan. J Pak Med Assoc. 2001; 51: 166-9.

14. Van Cuyck-Gandré $H$, Zhang HY, Tsarev SA, Warren RL, Caudill JD, Snellings NJ, et al. Short report: phylogenetically distinct hepatitis E viruses in Pakistan. Am J Trop Med Hyg: 2000; 62: 187-9.

15. Dufour DR, Lott JA, Nolte FS, Gretch DR, Koff RS, Seeff LB. Diagnosis and monitoring of hepatic injury. Recommendations for use of laboratory tests in screening, diagnosis and monitoring. Clinical Chemistry. 2000; 46: 2050-68.

16. Butt AS, Sharif F. Viral Hepatitis in Pakistan: Past, Present, and Future. Euroasian J Hepato-Gastroenterol. 2016; 6: 7081.

17. Malik IA, Tariq WUZ. Hepatitis E in Pakistan. Eastern Mediterranean Health Journal. 1996; 2: 121-8.

18. Teshale EH, Howard CM, Grytdal SP, Handzel TR, Barry V, Kamili S, et al. Hepatitis E Epidemic, Uganda. EID. 2010; 16: 126-9.

19. Das K, Agarwal A, Andrew R, Frösner G, Kar P. Role of hepatitis $E$ and other hepatotropic virus in aetiology of 
sporadic acute viral hepatitis: a hospital based study from urban Delhi. Eur J Epidemiol. 2000; 16: 937-40.

20. Azim W, Farooq W, Khan MQ, Shaheen N, lqbal M, Azim S. Biochemical pattern of liver function tests in Hepatitis $\mathrm{E}$ epidemic. Pak Armed Forces Med J. 2011; 61: 181-4.

21. Shrestha MP. Safety and efficacy of a recombinant Hepatitis E vaccine. NEJM. 2007; 356: 895-903. 